\title{
Nursing's Role in End of Life Discussions
}

\author{
Heidi Mason* \\ Clinical instructor, University of Michigan School of Nursing, USA \\ Received: 眥 January 25, 2018; Published: 眥 February 08, 2018 \\ *Corresponding author: Heidi Mason, Clinical instructor, University of Michigan School of Nursing, USA
}

\begin{abstract}
Every person deserves a dignified death. What this entails varies dramatically from patient to patient. Most people, however, never discuss their wishes regarding the care they desire for this very personal, final journey. As technology improves, as well as the ability to successfully treat almost any condition, both patients and clinicians alike have begun to ignore the reality of death. In our present culture discussing death has become taboo. Patients may think about the end of their lives but are unsure or uncomfortable broaching the topic with their medical staff and families. Additionally, many clinicians are uneasy with end-of-life (EOL) discussions and, consequently, avoid them entirely. It is, however, the ethical responsibility of health care providers to address their patient's wishes regarding EOL care. Clinicians need to take the initiative to begin the conversation regarding prognosis and care choices. They need to make the patients feel that they can comfortably discuss this delicate issue without fear of judgment, pressure, or the possibility of abandonment.
\end{abstract}

\section{Introduction}

End-of-life (EOL) conversations are an important part of patient care and should occur prior to a sentinel event. Patients should be able to voice their preferences and take an active role in determining their EOL care. If EOL discussions are not initiated early, patients are not given the opportunity to voice their wishes. The literature supports that most patients prefer to die at home and endorses that EOL discussions should begin earlier Baily, Periyakoil, 2017 Hickey \& Quinn, 2017.Unfortunately, as few as $20 \%$ of patients die at home Baily \& Periyakoil, 2017. A change is necessary to allow patients to die peacefully at home and prevent expensive, futile treatment that will ultimately cause increase suffering for the patient and their families.

One way to help patients avoid unnecessary distress at the EOL is through timely, compassionate and honest discussions. Although clinicians are concerned that EOL discussion may lead to fear and loss of hope, Clayton et al. [1] found that avoiding the truth did not promote hope, and that, in fact, honest and empathic communication empowered patients, as well as increased their hope. Additionally, the manner in which information is worded can be very potent. Carefully choosing words can make a difference in how the patient receives the information the clinician is giving them. For example, the word "futile" implies that the patient is not worthwhile or that

aggressive treatment is wasted on them. Using "appropriateness of care" relays the message but sounds more personal and caring [2]. Furthermore, the words "withdrawing care" may be misconstrued as no longer caring for the patient. Describing how a breathing tube would not improve the patient's status and may actually cause pain and discomfort can relay your ultimate concern with their loved one's well-being [3]. Care is never with drawn; it is just redirected toward symptom management and comfort. Communicating that to a patient conveys that you, as a clinician, still care and are invested in their life. Often patients and their families will worry more about what is not said, believing that the physician may not be able to face the truth. The literature supports that early and open discussions regarding EOL can empower patients, improve hope and quality of life, and help relieve families from making hard decisions on their loved one's behalf $[4,5]$. Decisions regarding life support or discontinuation of aggressive care should be made with the patient's input so that family members are not forced to make them on their own.

Education is another method of breaking down the barriers to timely EOL discussions. This is especially important because many nurses feel ill-equipped to address prognosis and EOL goals with patientsCostello [6], Milic etal.[7] conducted an eight-hourworkshop 
with ICU nurses. Nurses were able to practice communication skills during simulated experiences, followed by time for reflection. Burnout and self-care issues were also discussed. Following the workshop, participants described improved confidence and skills in assessing a patient's understanding of their prognosis and goals of care, as well as addressing their patient's emotional concerns. Additionally, they were able to actively participate in family meetings. It is clear that when nurses feel comfortable with their ability to discuss end-of-life goals with patients, they can begin to participate more fully in their patient's care. This will ultimately improve EOL care, as well as overall nursing satisfaction. Gillett and Bryan [8] developed a program called Quality End of Life Care for All (QELCA). This program involves bedside nurses shadowing hospice nurses and then engaging in six months of EOL training. Nurses who participated in this program stated that it had a significant impact on their practice. They felt more comfortable discussing EOL goals and caring for dying patients. They were more apt to initiate changes to improve their ability to begin timely discussions regarding a patient's goals of care. Glover et al. [9] conducted an Endof-Life Nursing Education Consortium (ELNEC) core course with BSN students. This course resulted in students with an improved knowledge of EOL care. Gillan et al [8] found that having nursing students participate in simulated end-of-life scenarios, followed by reflection, was beneficial in improving their comfort with EOL discussions. According to Coombs et al. [10], education in EOL care decreases the clinician's distress and improves their decisionmaking and communication skills. It also enhances teamwork at the bedside, while promoting patient-centered care. Clearly, education in EOL care is vital in improving the comfort level of nurses as they care for the dying patient. Not only will nurses begin to take on a larger role in planning their patient's care, but they will also begin to implement a more holistic approach to EOL care.

\section{Conclusion}

Regrettably, planning for the EOL often occurs in the final days or even hours when, in actuality, it should be occurring over an extended period of time, with a trusted provider well-known to the patient. Nurses are in a unique role to initiate EOL conversations. While a physician's focus is on treatment and cure, the goal of nursing care is centered on improving the patient's quality of life and the ability to function as normally and independently as possible [11-13]. This perfectly positions nurses to take the lead in assisting patients as they transition to the final stage of their lives. Timely discussions regarding EOL goals and wishes of patients is important in order to deliver competent, compassionate and ethical care $[14,15]$.

\section{References}

1. Clayton JM, Hancock K, Parker S, Walder S, Carrick S, et al. (2008) Sustaining hope when communicating with terminally ill patients and their families: A systematic review Psychooncology 17(7): 641-659.

2. Storch J (2015) Ethics in practice: At end of life - part 2. Can Nurse 111(7): 20-22.

3. Cramer CF (2010) To live until you die, Clinical Journal of Oncology Nursing 14(1): 53-56.

4. Greer JA, El Jabari A, Perl WF, Vicki A Jackson, Anthony Back, et al. (2016) Randomized trial of early integrated palliative and oncology care, Journal of Clinical Oncology 34(29): 104-104.

5. Larkin PJ (2010) Listening to the still small voice: The role of palliative care nurses in addressing psychosocial issues at end of life Progress in Palliative Care 18(6): 335-340.

6. Costello J (1995) Helping relatives cope with the grieving process Professional Nurse 11(2): 89-92.

7. Milic MM, Puntillo K, Turner K, Joseph D, Ryan R, et al. (2015) Communicating with patients' families and physicians about prognosis and goals of care. Am J Crit Care 24(4): e56-e64.

8. Gillan PC, van der Riet P, Jeong S (2016) Australian nursing students' stories of end-of-life care simulation, Nursing Health Science 18(1): 6469.

9. Glover TL, Garvin C, Neal is RM, City SW, Derrick DJ (2017) Improving end-of-life care knowledge among senior baccalaureate nursing students, American Journal of Hospice and Palliative Care, 34(10): 938945.

10. Coombs M, Long-Sutehall T, Shannon S (2010) International dialogue on end of life: challenges Nursing Critical Care, UK and USA 15(5): 234-240.

11. Wilson F, Ingleton C, Gott M, Gardiner C (2013) Autonomy and choice in palliative care: Time for a new model? J Adv Nursing 70(5): 1020-1029.

12. Pfeil TA, Laryionava K, Reiter-Theil S, Hiddemann W, Winkler EC (2014) What keeps oncologists from addressing palliative care early on with incurable cancer patients? An active stance seems key. Oncologist 20(1): 56-61.

13. Valente SM (2004) End-of-life challenges. Cancer Nursing 27(4): 314319.

14. Gillett K, Bryan L (2015) 'Quality End of Life Care for All' (QELCA): The national rollout of an end-of-life workforce development initiative, BM] Supportive and Palliative Care 6(2): 225-230.

15. Brown H, Johnston B, Östlund U (2011) Identifying care actions to conserve dignity in end-of-life care. British Journal of Community Nursing 16(5): 238-245. 
(C) This work is licensed under Creative

To Submit Your Article Click Here:

Submit Article

DOI: 10.32474/LOJNHC.2018.01.000101

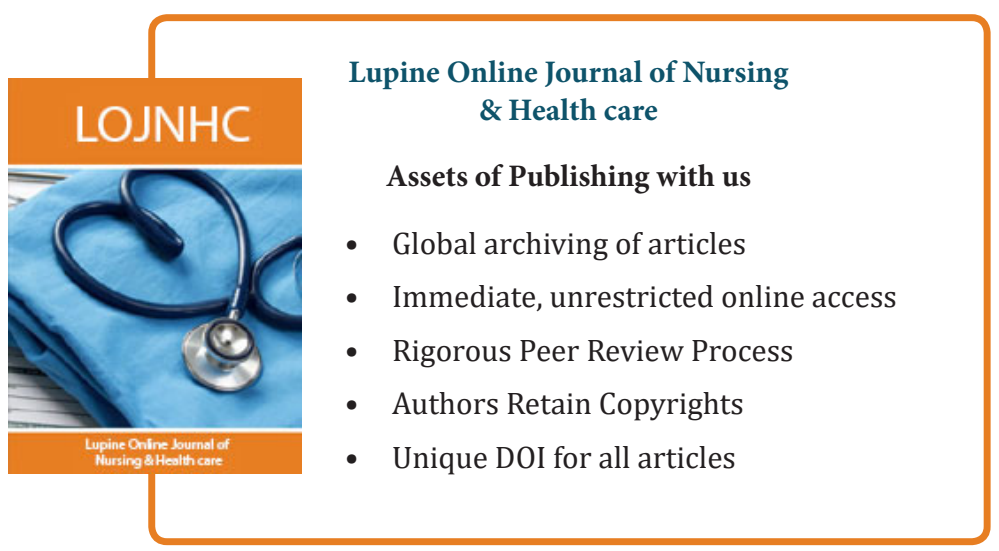

